\title{
ANÁLISE DE CRESCIMENTO EM CULTIVARES DE CANA-DE-AÇÚCAR EM CANA-SOCA NO NOROESTE DO PARANÁ NA SAFRA DE 2002/2003
}

\author{
ANALYSIS OF GROWTH IN CULTIVATING OF CANA-DE-AÇÚCAR IN CANE- \\ BEATS IN THE NORTHWEST OF THE PARANÁ IN THE HARVEST OF 2002/2003'
}

\author{
Darana Kelly Tramujas da SILVA ${ }^{2}$ \\ Edelclaiton DAROS ${ }^{3}$ \\ José Luis Camargo ZAMBON ${ }^{3}$ \\ Heroldo WEBER ${ }^{4}$ \\ Oswaldo Teruyo IDO ${ }^{3}$ \\ Kátia Christina ZUFFELLATO-RIBAS ${ }^{5}$ \\ Henrique Soares KOEHLER ${ }^{6}$ \\ Ricardo Augusto de OLIVEIRA7
}

\section{RESUMO}

O objetivo deste trabalho foi o estudar os índices de crescimento, através da análise de crescimento, das cultivares de cana-de-açúcar, RB845197, RB845210, RB855113, RB855536 e RB928064, em ciclo de primeira soca, em Paranavaí, região noroeste do Estado do Paraná, na safra 2002/2003. Foram realizadas sete avaliações, num intervalo de 50 dias, com coleta de plantas em um metro linear, por avaliação, sendo obtida a área foliar e massa seca de folhas e colmos. Foi utilizado o programa computacional ANACRES, para obtenção dos seguintes índices de crescimento: taxa de assimilação líquida, taxa de crescimento relativo, área foliar específica e razão de área foliar. Não houve diferença entre as cultivares quanto aos comportamentos das curvas dos índices estimados. Podendo-se concluir que a razão de área foliar e a taxa de assimilação líquida, tiveram igual influencia sobre as estimativas da taxa de crescimento relativo observadas. Com os resultados obtidos, pode-se formar três grupos de comportamento das cultivares estudadas: 1ํ) RB855536 e RB845197; 2º) RB845210 e RB928064 e 3ํ) RB855113.

Palavras-chave: Saccharum spp, cana-soca, acúmulo de massa seca.

\begin{abstract}
The objective of this work was to study the growth indices, through the analysis of growth, cultivating them of sugar cane of sugar, RB845197, RB845210, RB855113, RB855536 and RB928064, in cycle of first beats, in Paranavaí, region the northwest of the State of the Paraná, in harvest 2002/2003. Seven evaluations had been carried through, in an interval of 50 days, with collection of plants in a rowser meter, for evaluation, being gotten the foliar area and dry leaf mass and culm. Computational program ANACRES was used, for attainment of the following indices of growth: net assimilation rate, relative growth rate, leaf area specific and leaf area ratio. It did not have difference enters to cultivate them how much to the behaviors of the curves of the esteem indices. Being able itself to conclude that the leaf area ratio and net assimilation rate, had equal it influences on the observed estimates of relative growth rate. With the gotten results, it can be formed three groups of behavior of cultivating studied them: $1^{\circ}$ ) RB855536 and RB845197; 2ㅇ) RB845210 and RB928064 and 3ㅇ) RB855113.
\end{abstract}

Key-words: Saccharum spp, cane-beats, mass accumulation evaporates.

\footnotetext{
${ }^{1}$ Parte de dissertação do primeiro autor, apresentada na Universidade Federal do Paraná, para obter o grau de Mestre em Ciências no Curso de Pós Graduação em Agronomia, Produção Vegetal;

2Engenheira Agrônoma, Universidade Federal do Paraná, datrama@yahoo.com.br, autor para correspondência

${ }^{3}$ Engenheiro Agrônomo, Doutor, Universidade Federal do Paraná, Professor Adjunto;

${ }^{4}$ Engenheiro Agrônomo, Doutor, Universidade Federal do Paraná;

${ }^{5}$ Bióloga, Doutora, Universidade Federal do Paraná, Professora Adjunta;

${ }^{6}$ Engenheiro Florestal, Doutor, Universidade Federal do Paraná, Professor Adjunto;

${ }^{7}$ Engenheiro Agrônomo, Mestre, Universidade Federal do Paraná, Professor substituto.
} 


\section{INTRODUÇÃO}

O crescimento das plantas depende da conversão da energia luminosa e energia química, cuja intensidade é proporcional a interceptação capturada da luz pelo dossel da cultura. A cana-deaçúcar por ser uma planta C4, é altamente eficiente fotossinteticamente, e daí a importância das estimativas dos índices de crescimento, tais como, taxa de assimilação liquida (TAL), taxa de crescimento relativo (TCR), área foliar especifica (AFE), razão de área foliar (RAF), para melhor compreensão do desenvolvimento desta cultura.

Para poder obter estes índices faz-se o uso da análise de crescimento, que segundo Pereira e Machado (1987), representa a referência inicial na análise de produção das espécies vegetais, requerendo informações que podem ser obtidas sem a necessidade de equipamentos sofisticados. Tais informações são, a quantidade de material contido na planta toda e em suas partes (folhas, colmos, raízes e frutos) e o tamanho do aparelho fotossintetizante (área foliar), obtidos em intervalos de tempo regulares durante o desenvolvimento fenológico da planta (URCHEl et al., 2000).

Como o crescimento é avaliado por meio de variações em tamanho, de algum aspecto da planta, geralmente morfológico, isso evidencia que a análise de crescimento esta baseada no fato que $90 \%$ em média da matéria seca acumulada pelas plantas ao longo do seu crescimento, resulta da atividade fotossintética, sendo que esta passa a ser componente fisiológico de maior importância neste tipo de estudo (BENINCASA, 1988).

Segundo Gomide e Gomide (1999) o balanço fotossíntese-respiração, determina a quantidade de assimilados disponíveis para o crescimento vegetal (TAL), entretanto a alocação preferencial de carbono pelas diferentes frações da planta - folhas, colmo e sistema radicular -, condicionada pelo meio e/ou manejo, determina variações nos índices de crescimento AFE, RAF e IAF. Assim as estimativas desses índices podem fornecer subsídios para o entendimento das adaptações experimentadas pelas plantas sob diferentes condições de meio: luz, temperatura, umidade e fertilidade do solo. Assim a análise de crescimento auxilia a interpretação das diferenças entre genótipos e de suas adaptações ao meio em que são cultivados e ao manejo.

Maior alocação de assimilados para síntese de folhas, resulta maiores valores de razão de peso folha e, conseqüentemente, aumento da RAF, que, toda via, também pode advir de elevação da AFE, em resposta a adaptação da planta a condição de baixa luminosidade ou baixa fertilidade de solo (POORTER, 1989).

Como TAL e RAF são componentes da TCR, a observação destes vai permitir concluir, dependendo da cultura e das condições do meio no qual essa se encontra, qual destes índices vai influenciar mais na variação, ou se terão igual participação na determinação da TCR.

Gomide e Gomide (1999), estudando Panicum maximum, observaram que tanto RAF como TAL tiveram igual influencia sobre as estimativas de TCR, entretanto em Feijão-fava a variação na TCR de um ano para outro foi mais dependente de TAL que RAF (COSTA et al., 1997).

As informações sobre o crescimento e desenvolvimento da cana-de-açúcar para o Estado do Paraná, são insuficientes para a compreensão do ciclo da cultura. A aplicação do estudo de análise de crescimento em cultivares, pode fornecer informações precisas e confiáveis sobre o crescimento, em condições de desenvolvimento para o Estado.

O presente estudo teve como objetivo, estudar o crescimento e desenvolvimento, através da análise de crescimento, de cultivares de cana-de-açúcar em ciclo de primeira soca.

\section{METODOLOGIA}

O trabalho foi desenvolvido na Estação de Paranavaí, localizada no Noroeste do Estado, no terceiro planalto, numa Latitude $23^{\circ} 05^{\prime} \mathrm{S}$, Longitude $52^{\circ} 26^{\prime} \mathrm{W}$ e Altitude de $480 \mathrm{~m}$. A classe de solo do experimento é LATOSSOLO VERMELHO Distrófico de textura arenosa, sendo solo de maior representatividade na região, suas características químicas na época do plantio, abril/2001 eram: na camada de $0-30 \mathrm{~cm}$ de profundidade, $\mathrm{pH}=6,2 ; \mathrm{P}=8 \mathrm{mg} /$ $\mathrm{dm}^{3} ; \mathrm{K}=0,15 \mathrm{cmolc} / \mathrm{dm}^{3} ; \mathrm{Ca}=1,1 \mathrm{cmolc} / \mathrm{dm}^{3}, \mathrm{Mg}=0,9$ $\mathrm{cmolc} / \mathrm{dm}^{3} ;$ e $\mathrm{Al}=0,0 \mathrm{cmolc} / \mathrm{dm}^{3} ;$ Físicas : areia $=82 \%$; silte $=1 \%$ e argila $=17 \%$,e logo após o corte da cana planta (set/2002), foi realizada adubação de cobertura utilizando-se da fórmula 25-0-25.

Os dados de temperatura e precipitação durante a realização do trabalho estão representados na Figura 1. O período de condução do experimento a campo foi de set/2002 a ago/2003, totalizando 350 dias de ciclo da primeira soca, ou seja, 350 dias após o corte da planta. As avaliações foram feitas aos 50, $100,150,200,250,300$ e 350 dias após o corte (DAC), entre 22/10/2002 a 28/08/2003. Cada parcela experimental foi constituída por 4 sulcos de $8 \mathrm{~m}$ de comprimento, espaçado de $1,40 \mathrm{~m}$ entre si e $2 \mathrm{~m}$ entre parcelas, em cada sulco plantou-se 18 gemas por metro linear. As cultivares estudadas foram RB855113, RB928064, RB845210, RB845197 e RB855536, a Tabela 1 resume as características de cada uma das cultivares. Em cada avaliação foi marcado um metro linear de um dos sulcos de cada parcela, e todas as plantas deste metro tiveram sua folha +3 medidas (comprimento e largura) para obtenção da área foliar através da fórmula proposta por Hermann \& Câmara (1999) $\mathrm{AF}=\mathrm{C} \times \mathrm{L} \times 0,75 \times(\mathrm{NF}+2)$, onde: $\mathrm{AF}$ - área foliar; $C$ - comprimento da folha +3 ; $L$ - largura de folha $+3 ; 0,75$ - fator de forma; NF - número de folhas abertas com pelo menos $20 \%$ de área verde na planta (folha $0 \mathrm{a}+7$ ) - depois disso as plantas foram cortada rente ao solo, identificadas e levadas ao laboratório 
para serem separadas em folha e colmo, secas a estufa de ar forçado para obtenção de sua massa seca, com o número de perfilhos por metro linear podese estima o numero de plantas por metro quadrado.
Estes dados coletados foram analisados pelo programa computacional ANACRES (PORTES e CASTRO, 1991), para obtenção dos índices: TAL, TCR, RAF e AFE.

TABELA 1 - Resumo das principais características das cultivares.

\begin{tabular}{lcccc}
\hline CULTIVAR & CRESCIMENTO & PERFILHAMENTO & CICLO & COLHEITA \\
\hline RB855113 & Lento & + & Médio & JUL/AGO/SET \\
RB845210 & Lento & - & Médio & JUL/AGO \\
RB845197 & Rápido & + & Médio & JUN/JUL \\
RB928064 & Rápido & + & Médio/Tardio & AGO/SET/OUT \\
RB855536 & Médio & + & Médio & JUL/AGO/SET \\
\hline
\end{tabular}

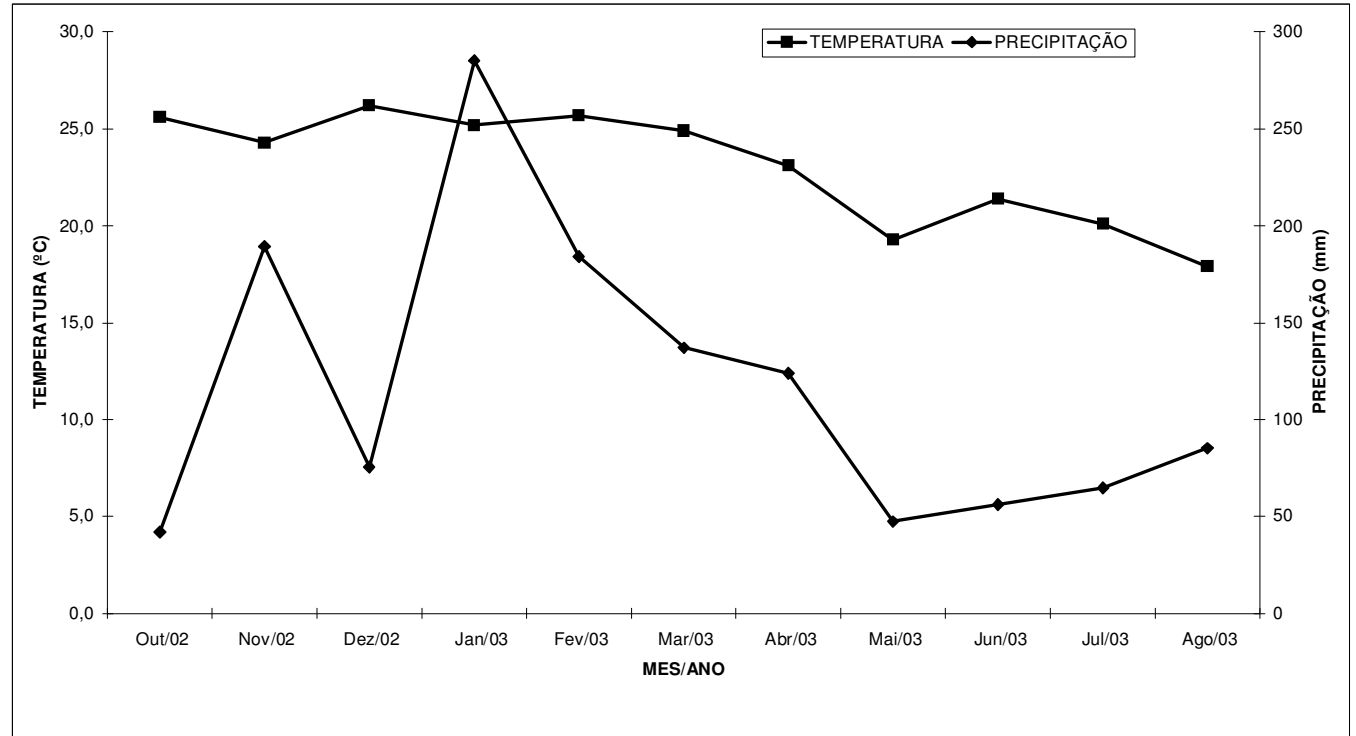

FIGURA 1 - Dados climatológicos, de temperatura média e precipitação no período de outubro/2002 a agosto/2003. Estação Meteorológica IAPAR / SIMEPAR, Paranavaí, PR.

\section{RESULTADOS}

\section{Taxa de assimilação líquida - TAL}

As estimativas de TAL revelam, valores máximos aos 100 DAC, seguido de uma brusca queda até $150 \mathrm{DAC}$, passando para uma suave redução até os 250 DAC e ainda um leve aumento até os 350 DAC. O comportamento das cultivares é muito semelhante, apresentando valores e curvas muito próximas entre si (Figura 2). Esse alto valor, na fase inicial do desenvolvimento da cultura, decorreu segundo Gomide e Gomide (1999), de características de área foliar pequena e de alta capacidade fotossintética, própria de gramíneas tropicais, assim como as condições favoráveis de temperatura e radiação e ainda de adequada disponibilidade de nutrientes. Essa progressiva redução da TAL pode ser explicada em função da redução na capacidade fotossintética das folhas em expansão, em razão do progressivo sombreamento mutuo (WILSON e LUDLOW, 1970; WOLEDGE e LEAFE, 1976 e WOLEDGE,1978), bem como na redução da eficiência fotossintética do dossel, em decorrência da avançada idade média das folhas (WOLDGE e LEAFE, 1976, PARSONS et al., 1983), além do progressivo aumento da carga respiratória de manutenção (GOMIDE e GOMIDE, 1999).

Observando os resultados de TAL, pode-se agrupar as cultivares conforme seus comportamentos, sendo as RB855113 e RB845210 integrantes do primeiro grupo, apresentando valores de final de ciclo, próximos aos valores encontrados no início de ciclo de desenvolvimento, as cultivares RB855536 e RB928064, apresentaram valores que decrescem bruscamente até os 200 DAC, e decrescem suavemente até os 350 DAC, no final do ciclo, já a cultivar RB845197 apresentou valores continuamente decrescentes até o final do ciclo. 
SILVA, D.K.T. et al. Análise de crescimento em cultivares...

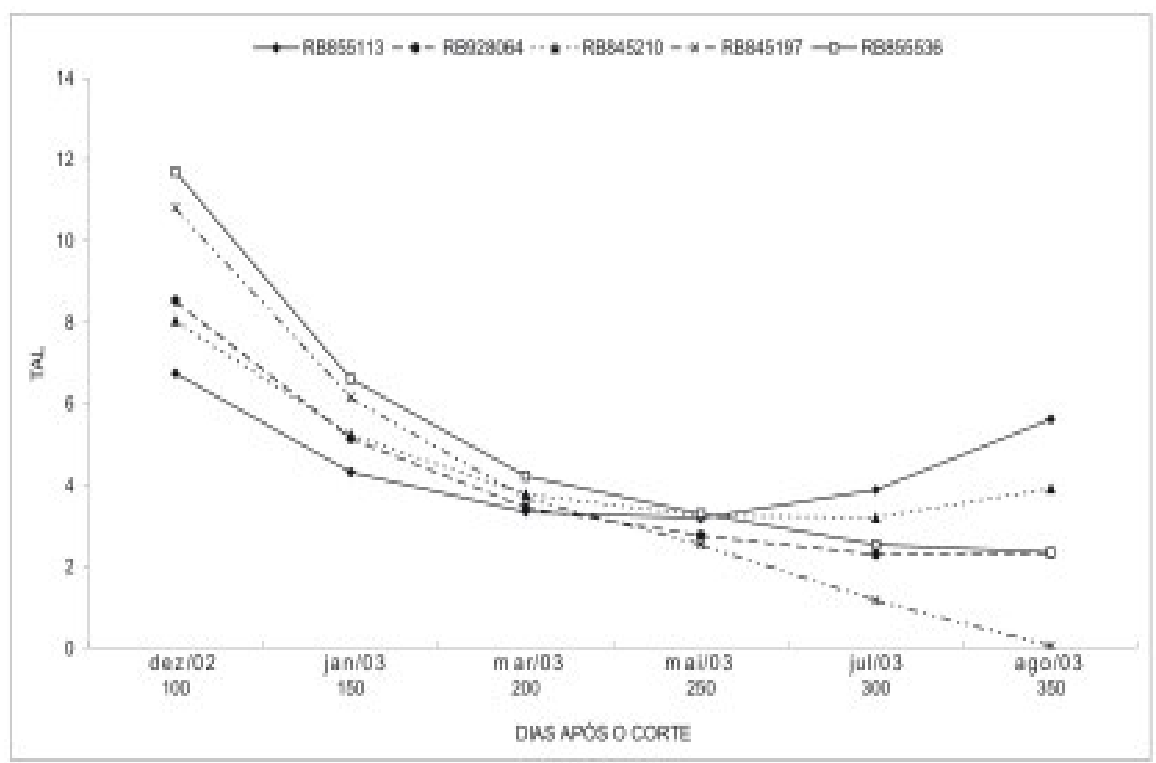

FIGURA 2 - Taxa de assimilação líquida de cinco cultivares de Cana-de-Açúcar, em primeira soca, sete épocas de amostragem. Análise destrutiva. Estação Experimental de Paranavaí, SCA-UFPR, 2002/2003.

\section{Razão de área foliar - RAF}

As curvas de razão de área foliar, que estão representadas na Figura 3 , revelam um comportamento muito semelhante entre as cultivares estudadas, mostrando seus máximos valores aos 100 DAC, decrescendo constantemente até a colheita aos 350 DAC. Porém no início do desenvolvimento da cultura, as cultivares se dividiram em três grupos de comportamento, o da RB855113, que apresentou os maiores valores, o grupo das cultivares RB928064 e RB845210, com valores medianos e o das RB855536 e RB845197, que tiveram valores iniciais inferiores às demais, porém com o decorrer do desenvolvimento da cultura, essas diferenças foram diminuindo, até o final do ciclo, e aos 350 DAC as cultivares apresentaram valores próximos entre si. Assim constata-se, neste estudo, queda para este índice fisiológico, à medida que a planta se desenvolve, e a potencialidade de produção de assimilação decresce igualmente os resultados encontrados por Rossetto e Nakagawa, (2001). De acordo com Rodrigues (1982), a RAF é uma medida relativa do aparelho assimilador, ou seja, ela representa a dimensão relativa do aparelho fotossintético, sendo bastante apropriada a avaliação dos efeitos genotípicos, climáticos e de comunidades vegetais. Este índice fisiológico expressa, também, a área foliar útil para a fotossíntese, sendo em componente morfofisiológico da análise de crescimento (BENINCASA, 1988).

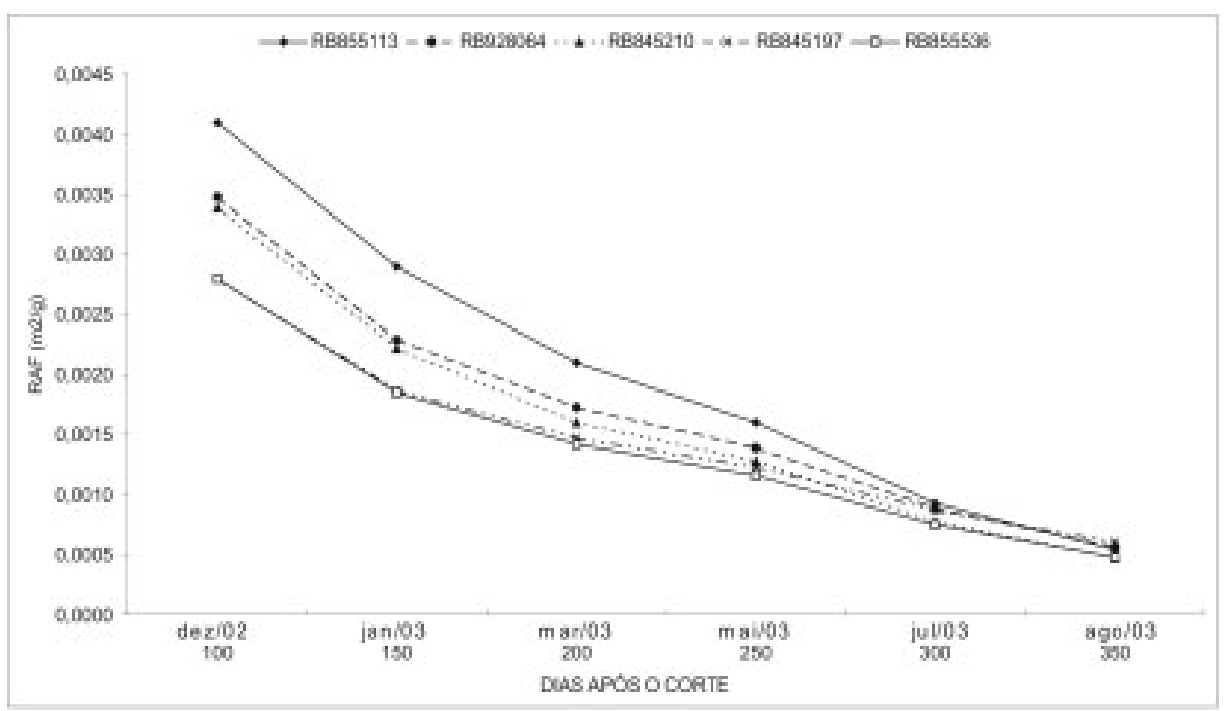

FIGURA 3 - Razão de área foliar de cinco cultivares de Cana-de-Açúcar, em primeira soca, sete épocas de amostragem. Análise destrutiva. Estação Experimental de Paranavaí, SCA-UFPR, 2002/2003. 


\section{Taxa de crescimento relativo -TCR}

A variação da taxa de crescimento relativo está representada por uma função exponencial negativa (Figura 4), com valor máximo de $0,034 \mathrm{~g} / \mathrm{g} / \mathrm{dia}$ alcançado pela cultivar RB845197, aos 100 DAC, decrescendo com o tempo e estabilizando-se aos 300 DAC, já no final do ciclo. O comportamento da curva foi semelhante ao encontrado por Gava et al. (2001) em cana - soca, porém os valores inferiores, onde a TCR máxima encontrada por eles foi de $0,135 \mathrm{~g} / \mathrm{g} /$ dia. Verifica-se que o comportamento entre as cultivares foi muito semelhante, não sendo possível a separação das cultivares estudadas em grupos de comportamento. A TCR diminuiu à medida que a planta cresceu, devido, entre outros fatores, ao aumento de competição intra-específica pelos principais fatores ambientais responsáveis pelo crescimento vegetal, tais como: água, luz, nutrientes, difusão de $\mathrm{CO}^{2}$ dentro do estande (GAVA et al., 2001). Essa diminuição contínua da TCR pode ser explicada pela elevação da atividade respiratória e pelo autosombreamento, cuja importância aumenta com a idade da planta. Além disso, na fase final da cultura, o crescimento se torna negativo em função da morte das folhas e gemas (MILTHORPE e MOORBY, 1974). Visto que TCR = RAF $\times$ TAL, a semelhança das curvas para estes três índices (Figuras 02,03 e 04) sugere que durante a fase de estabelecimento deste estudo, tanto RAF como TAL tiveram igual influencia sobre as estimativas de TCR observadas, isso foi encontrado também por Gomide e Gomide (1999) em Panicum maximum, entretanto em feijão-fava a variação na TCR de um ano para outro foi mais dependente de TAL que RAF (COSTA et al., 1997). Porém segundo Poorter. (1989), a RAF é o principal componente da TCR, determinando sua variação.

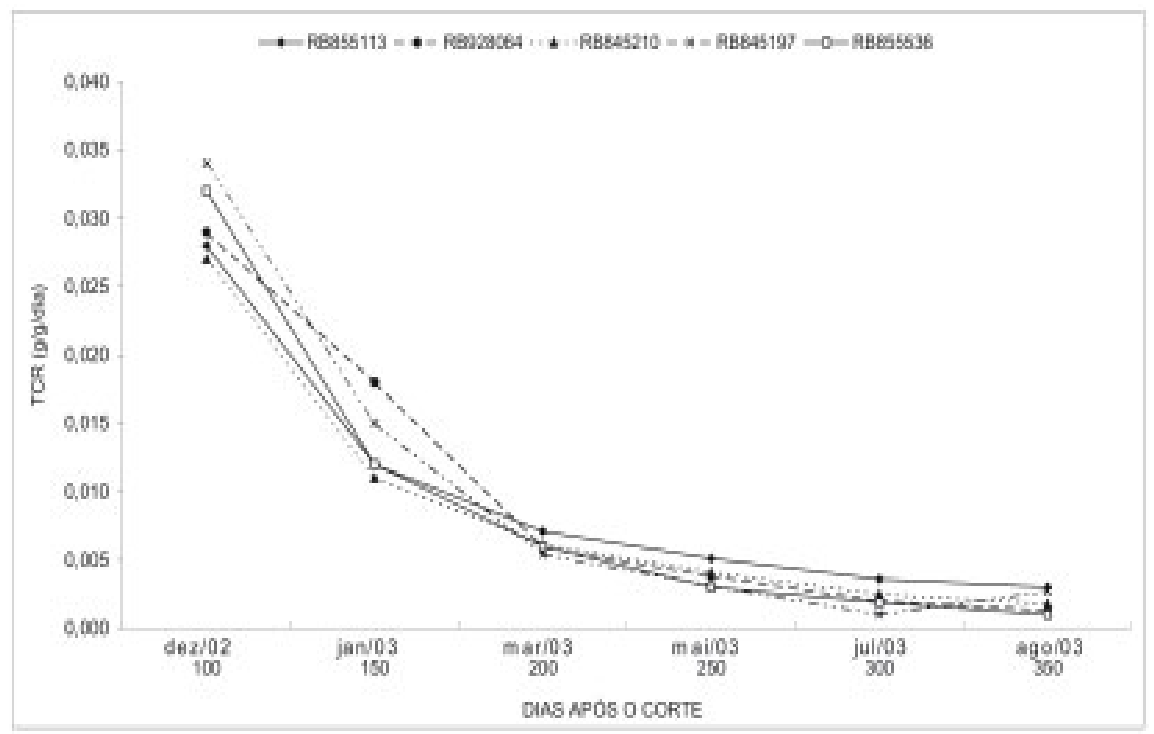

FIGURA 4 - Taxa de crescimento relativo de cinco cultivares de Cana-de-Açúcar em primeira soca, sete épocas de amostragem. Análise destrutiva. Estação Experimental de Paranavaí, SCA - UFPR, 2002/2003.

\section{Área folicular específica - AFE}

A Figura 5 mostra os resultados obtidos para AFE, para as cultivares da cultura de cana-deaçúcar. Pode-se observar que os comportamentos entre as cultivares estudadas são muito semelhantes, apresentando valores maiores no início do ciclo da cultura, pelo acúmulo de reservas nas folhas, quando as cultivares dividiram-se em três grupos de comportamento, o da RB855113, que apresentou valores superiores às demais, o grupo das cultivares RB928064 e RB845210, com valores medianos e o das RB855536 e RB845197, que tiveram valores iniciais inferiores às demais, porém com o decorrer do desenvolvimento da cultura, essas diferenças foram diminuindo, até o final do ciclo, e aos 350 DAC as cultivares apresentaram valores próximos entre si. Os valores foram decrescendo com o desenvolvimento da cultura, mostrando que a cultura da cana-de-açúcar transloca suas reservas das folhas para outras partes da planta, principalmente nos colmos, comportamento esse observado também por Aguiar Netto et al. (1999), na cultura da batata sob diversas lâminas de irrigação. De acordo com Radford (1967), a AFE representa as diferenças no espessamento foliar, ou seja, permite verificar se as plantas estão acumulando fotoassimilados em suas folhas ou translocando-os para outros órgãos. Considerando que a área foliar é um componente anatômico de uma espécie vegetal, pois está relacionado à composição interna 
(número ou tamanho das células do mesofilo foliar), verifica-se que na verdade o inverso da AFE reflete a espessura das folhas (BENINCASA, 1988). Assim parece lógico que no início do desenvolvimento vegetativo os valores da AFE sejam maiores, caindo a seguir e tornando-se constante posteriormente, conforme analisou Rodrigues (1990).

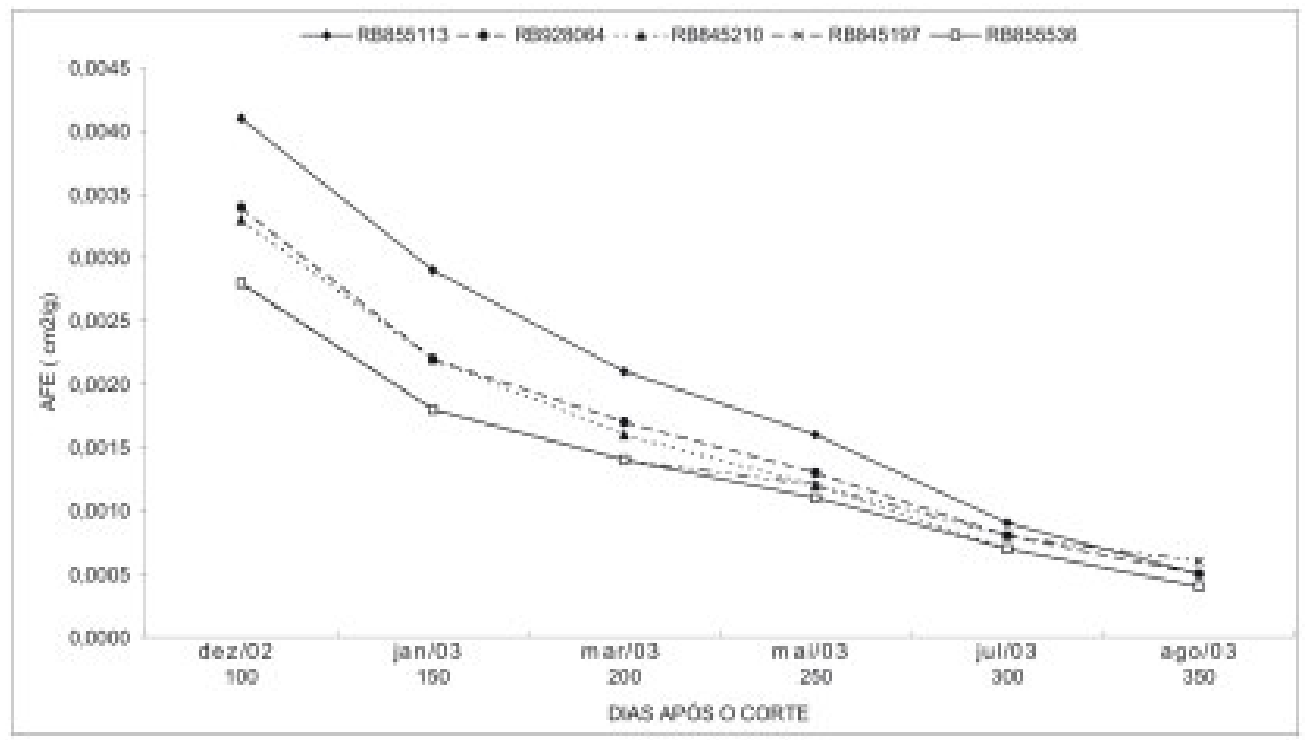

FIGURA 5 - Área foliar específica de cinco cultivares de Cana-de-Açúcar, em primeira soca, sete épocas de amostragem. Análise destrutiva. Estação Experimental de Paranavaí, SCA - UFPR, 2002/2003.

Como a RAF é a medida do aparelho fotoassimilador, que á a folha, e seus resultados mostraram que com o passar do tempo a capacidade fotossintética da cana decresce, e a AFE representa onde a planta está acumulando suas reservas, que seus valores também decrescem com o passar do tempo, pode-se dizer que, a capacidade fotossintética diminui com o desenvolvimento da cultura da cana pois, a planta está desenvolvendo outros órgãos, que não foliares, que demandam energia, e que são chamados de drenos, como os colmos, raízes e folhas velhas, a parece redundante afirmar que a cana acumula suas reservas no colmo e rizomas, sendo estes órgãos, drenos da energia acumulada pelas folhas, como pode ser observado pelos dados de RAF e AFE.

Observando as Figuras 2, 3, 4 e 5, pode-se agrupar as cultivares estudadas conforme seus comportamentos, e assim formar três grupos; o das cultivares RB855536 e RB845197, o das cultivares RB845210 e RB928064 e o da cultivar RB855113.

\section{CONCLUSÕES}

Não houve diferença entre as cultivars quanto aos comportamentos das curvas dos índices estimados. Pôde-se concluir também que a RAF e TAL tiveram igual influência sobre as estimativas de TCR observadas. Com este estudo pode-se entender melhor como ocorre e o que influencia na cultura da cana-de-açúcar.

Quanto aos índices fisiológicos da análise de crescimento, pode-se formar três grupos de comportamento das cultivares estudadas: $1^{\circ}$ ) RB855536 e RB845197; 2º) RB845210 e RB928064 e $\left.3^{\circ}\right)$ RB855113.

\section{REFERÊNCIAS}

1. AGUIAR NETTO, A.O.; RODRIGUES, J.D.; NASCIMENTO JÚNIOR, N.A. Análise de crescimento na cultura da batata (Solanun tuberosum ssp Tuberosum) submetida a diferentes lâminas de irrigação: razão tubérculo- parte aérea, área foliar específica, razão de área foliar e razão de massa foliar. Irriga, Botucatu, v.4, n.1 p.13-24, 1999.

2. BENINCASA, M.M.P. Análise de crescimento de plantas: noções básicas. Jaboticabal: Funep, 1988. 42p.

3. COSTA, L.C.; MORISON, J.; DENNETT, M. Effects of the weather on growth and radiation intercepted by Faba bean. Pesquisa Agropecuária Brasileira, v.32, n.3, p. 277-281, 1997.

4. GAVA, G.J.C.; TRIVELIN, P. C.; OLIVEIRA, M. W.; PENATTI, C. P. Crescimento e acúmulo de nitrogênio em cana-de-açúcar cultivada em solo coberto com palhada. Pesquisa Agropecuária Brasileira, Brasília, v.36, n.11, p.1347-1354, 2001. 
SILVA, D.K.T. et al. Análise de crescimento em cultivares...

5. GOMIDE, C. A. M.; GOMIDE, J. A. Análise de Crescimento de Cultivares de Panicum maximum Jacq. Revista Brasileira de Zootecnia, Viçosa, v.28, n.4, p.675-680, 1999.

6. HERMANN, E.R.; CÂMARA, G.M.S. Um método simples para estimar a área foliar de cana-de-açúcar. Stab. Açúcar, Álcool \& Subprodutos, v.17, n.5, p.32-34, 1999.

7. MILTHORPE, F. L.; MOORBY, J. An introduction to crop physiology. Crambridge, Grã-Bretanha: Cambridge University, 1974. 201p.

8. PARSONS, A.; LEAFE, E. L.; COLLETT, B. The physiology of grass production under grazing. II - Photosynthesis. Crop growth na animal intake of continuous grazed sward. J. Appl. Ecology, 20(1):p.127-139. 1983.

9. PEREIRA, A.R.;MACHADO, E.C. Análise quantitativa do crescimento de comunidade de vegetais. Campinas: Instituto Agronômico, 1987.33p.

10. POORTER, $\mathrm{H}$. Interspecific variation in relative growth rate: on ecological causes and physiological consequences. In: Lambers, $\mathrm{H}$. et. al. Causes and consequences of variation in growth rate and productivity of higher plants. H. ague: Netherlands, p.45-67, 1989

11. PORTES, T.A.; CASTRO JÚNIOR, L.G. Análise de crescimento de plantas: um programa computacional auxiliar. Revista Brasileira de Fisiologia Vegetal, Brasília, v.3, p. 53-56, 1991.

12. RADFORD, P.J. Growth analysis formulase - their use and abuse, Crop Science, Madson, v.7, n.3, p. 171-175, 1967.

13. RODRIGUES, J.D. Análise de crescimento de plantas de soja (Gycine max. L. Merri) Submetidas à carências nutricionais. Rio Claro, 165p. 1982. (Dissertação de Mestrado).

14. RODRIGUES, J.D. Influencia de diferentes níveis de cálcio, sobre o desenvolvimento de plantas de estilosantes (Stylosanthes guyanensis (Aubl). SW. cv. Cook), em cultivo hidropônico, Botucatu; UNESP. FCA. 180p. (Tese de Livre Docência), 1990.

15. ROSSETTO, C.A.V.; NAKAGAWA, J. Índices da análise de crescimento em função das condições de cultivo de Aveia preta (Avena stigosa Scher). Revista de Agricultura, Piracicaba, v.76, fase 2, 2001.

16. URCHEI, M.A.; RODRIGUES, J.D.; STONE, L.F. Análise de crescimento de duas cultivares de feijoeiro sob irrigação, em plantio direto e preparo convencional. Pesquisa Agropecuária Brasileira, v.35, n.3, p.497-506, 2000.

17. WILSON, G. L. ; LUDLOW. M. M. Net photosynthesis rates of tropical grass and legume leaves. In: NORMAN, M. J. T. (Ed.) Int. Grassland Congress, 11, 1970. Surfers Paradise Queensland. Proceedings... Austrália: CSIRO. p. 534-538. 1970.

18. WOLEDGE, J. The effect of shading during vegetative and reproductive growth on photosynthetic capacity of leaves in a grass sward. Annals of Botany, 42(181):p.1085-1089. 1978.

19. WOLEDGE, J.; LEAFE, E. L. Single leaf and canopy photosynthesis in a ryegrass sward. Annals of Botany. 40(68):p.773-783. 1976.

Recebido em 10/02/2005 Aceito em 13/10/2005 